\title{
Acute kidney injury after coronary artery bypass grafting: Does rhabdomyolysis play a role?
}

\author{
Umberto Benedetto, MD, ${ }^{\mathrm{a}}$ Emiliano Angeloni, MD, ${ }^{\mathrm{a}}$ Remo Luciani, MD, ${ }^{\mathrm{b}}$ Simone Refice, MD, ${ }^{\mathrm{a}}$ \\ Manuel Stefanelli, MD, ${ }^{\mathrm{a}}$ Cosimo Comito, MD, ${ }^{\mathrm{a}}$ Antonino Roscitano, MD, ${ }^{\mathrm{a}}$ and Riccardo Sinatra, $\mathrm{MD}^{\mathrm{a}}$
}

\begin{abstract}
Objective: In clinical situations in which rhabdomyolysis is common, renal dysfunction association with myoglobinemia is well described. After coronary artery bypass grafting, a rapid increase in serum myoglobin concentration is generally seen, but whether it might independently increase the risk of acute kidney injury remains to be determined.
\end{abstract}

\begin{abstract}
Methods: The study population consisted of 731 consecutive patients undergoing coronary artery bypass grafting. Creatine kinase, myoglobin, and creatinine concentrations were assessed in each patient preoperatively and postoperatively. Acute kidney injury was defined as an absolute increase in serum creatinine concentration of 0.3 $\mathrm{mg} / \mathrm{dL}$ or greater.

Results: Overall, 295 (40.3\%) of 731 patients had acute kidney injury. Patients' risk profiles were significantly worse in those with acute kidney injury, and $31(4.2 \%)$ of 731 patients required dialysis. Acute kidney injury was associated with a higher increase in serum myoglobin concentration after 1 hour from aortic declamping $(534 \mu \mathrm{g} / \mathrm{mL}$ [interquantile range, $354-733 \mu \mathrm{g} / \mathrm{mL}$ ] vs $377 \mu \mathrm{g} / \mathrm{mL}$ [interquantile range, $278-528 \mu \mathrm{g} / \mathrm{mL}$ ], $P<.0001$ ), which persisted at 24 and at 48 hours. After adjusting for confounding factors, myoglobin concentration was found to independently predict postoperative acute kidney injury (odds ratio, $1.0011[1 \mu \mathrm{g} / \mathrm{mL}$ increase]; 95\% confidence interval, 1.0003-1.0019; $P=.005)$, and this result persisted when patients with perioperative myocardial infarction were excluded from the analysis (odds ratio, $1.0007 ; 95 \%$ confidence interval, 1.0002-1.0009; $P=.01$ ). Myoglobin concentration had a better accuracy to discriminate patients having acute kidney injury than creatine kinase concentration at any time.
\end{abstract}

Conclusions: An increase in laboratory findings of muscle injury postoperatively, especially serum myoglobin concentration, predicts the incidence of acute kidney injury and renal replacement therapy requirement, as reported in other surgical settings. Perioperative myocardial injury cannot totally explain the occurrence of increased myoglobinemia. These results suggest an important role of skeletal muscle breakdown and necrosis in determining an increased myoglobinemia concentration after coronary artery bypass grafting. ( $\mathrm{J}$ Thorac Cardiovasc Surg 2010;140:464-70)

Acute kidney injury (AKI) after coronary artery bypass grafting $(\mathrm{CABG})$ remains a significant cause of perioperative morbidity and mortality. ${ }^{1}$ The postoperative incidence of AKI has been assessed by using a variety of definitions, with estimates ranging from $5 \%$ to $40 \% .{ }^{1}$ Despite extensive research in the prediction and treatment of this disease, there has been limited success in altering patient outcomes. ${ }^{1}$ AKI is believed to be mainly related to the adverse effects of cardiopulmonary bypass (CPB), such as hypoperfusion and activation of both innate and adaptive immune responses that can extend renal injury. ${ }^{1}$ Off-pump CABG, avoiding the del-

From the Cardiac Surgery Department, ${ }^{\text {a }}$ University of Rome La Sapienza, Policlinico S. Andrea, Rome, Italy, and the Nephrology Unit, ${ }^{\mathrm{b}}$ G. Rummo Hospital, Benevento, Italy.

Disclosures: None.

Received for publication Dec 3, 2009; revisions received Feb 6, 2010; accepted for publication March 20, 2010; available ahead of print April 23, 2010.

Address for reprints: Umberto Benedetto, MD, Cardiac Surgery Department, II School of Medicine, University of Rome “La Sapienza," Via di Grottarossa 1035, 00100, Rome, Italy.

$0022-5223 / \$ 36.00$

Copyright (c) 2010 by The American Association for Thoracic Surgery doi:10.1016/j.jtcvs.2010.03.028 eterious effect of extracorporeal circulation, might reduce the incidence of renal dysfunction after surgical intervention. However, a beating heart technique can be challenging and cumbersome and has been shown to have inferior results with respect to long-term graft patency. ${ }^{2}$ Therefore we have broadened our search for potential causes of kidney injury after on-pump CABG beyond those classically posited.

In clinical situations in which rhabdomyolysis is common, especially those such as burn and severe muscle trauma, renal dysfunction association with myoglobinemia is well described. ${ }^{3}$ In surgical settings rhabdomyolysisinduced AKI has been recently described after urologic ${ }^{4,5}$ and thoracoabdominal aortic surgery. ${ }^{6,7}$

After $\mathrm{CABG}$ with $\mathrm{CPB}$, a marked increase in laboratory findings of muscle injury, such as serum creatine kinase (CK) and myoglobin concentrations, is generally seen, but whether this phenomenon can independently affect postoperative kidney function remains to be determined. In addition, serum $\mathrm{CK}$ and myoglobin concentration increases are generally considered a consequence of perioperative myocardial injury, but no previous study has investigated 


$$
\begin{aligned}
& \text { Abbreviations and Acronyms } \\
& \begin{aligned}
\text { ACEI/ } & \text { angiotensin-converting enzyme } \\
\text { ARB } & \text { inhibitor/angiotensin receptor blocker } \\
\text { AKI } & \text { acute kidney injury } \\
\text { CABG } & =\text { coronary artery bypass grafting } \\
\text { CI } & =\text { confidence interval } \\
\text { CK } & =\text { creatine kinase } \\
\text { CPB } & =\text { cardiopulmonary bypass } \\
\text { cTnI } & =\text { cardiac troponin I } \\
\text { GFR } & =\text { glomerular filtration rate } \\
\text { IQR } & =\text { interquantile range } \\
\text { LOS } & =\text { low cardiac output syndrome } \\
\text { OR } & =\text { odds ratio } \\
\text { RBC } & =\text { red blood cell } \\
\text { ROC } & =\text { receiver operating characteristic } \\
\text { RRT } & =\text { renal replacement therapy }
\end{aligned}
\end{aligned}
$$

whether skeletal muscle might represent a potential source because of intraoperative hypoperfusion or unrelieved pressure during prolonged operative time, as occurs in other surgical settings. ${ }^{8}$

In the present analysis we sought to better characterize the correlation between laboratory findings of muscle injury after $\mathrm{CABG}$ with $\mathrm{CPB}$ and the postoperative incidence of AKI.

\section{MATERIALS AND METHODS \\ Patient Population}

This study was reviewed and approved by the Institutional Review Board of the University of Rome, and a waiver of consent was granted. The authors have no conflicts of interest to disclose.

In the present study we analyzed consecutive patients undergoing isolated CABG at our institution between May 2004 and May 2009 meeting the following criteria: (1) all procedures occurred during CPB; (2) no preoperative renal failure requiring dialysis was present; and (3) no prior cardiac surgeries were recorded. The study population consisted of 731 patients (median age, 68 years [IQR, 59-73 years]; 128 [17.5\%] of 731 were women).

\section{Biochemical Analysis}

Serum CK and myoglobin concentrations are generally used as indicators of myocyte injury in patients with rhabdomyolysis. Therefore both of them were assessed in each patient preoperatively (before sternotomy), early postoperatively (at 1 hour after declamping), and at 24 hours. In addition, cardiac troponin I (cTnI) concentrations were evaluated as a specific marker of acute myocardial injury.

Blood samples were collected from each patient, and samples were immediately cooled to $4^{\circ} \mathrm{C}$ and centrifuged at $3000 \mathrm{rpm}$ for 10 minutes at $4^{\circ} \mathrm{C}$. Sera were stored at $270^{\circ} \mathrm{C}$ until assay. Myoglobin, CK, and cTnI concentrations were measured by using immunometric technology (Diagnostic Products Corp, Los Angeles, Calif).

\section{Definitions}

Data were prospectively collected and recorded in an electronic database by physicians. Baseline serum creatinine values were defined as the values recorded just before surgical intervention. Serum creatinine values were taken at 1 hour after declamping and measured at least once every 24 hours. The 4-variable Modified Diet and Renal Disease equation was used to estimate the baseline glomerular filtration rate (GFR). ${ }^{9}$ Based on National Kidney Foundation definitions, ${ }^{10}$ chronic kidney disease was defined as a GFR of less than $60 \mathrm{~mL} / \mathrm{min} / 1.73 \mathrm{~m}^{2}$. According to the consensus definition proposed by the Acute Kidney Injury Network, ${ }^{11}$ AKI was defined as an abrupt (within 48 hours) reduction in kidney function defined as an absolute increase in serum creatinine concentration of $0.3 \mathrm{mg} / \mathrm{dL}$ or greater $(\geq 26.4$ $\mu \mathrm{mol} / \mathrm{L}$ ) or a percentage increase of $50 \%$ or greater (1.5-fold from baseline). We did not use urine output in defining AKI.

Consulting nephrologists made decisions about implementing postoperative renal replacement therapy (RRT). Indications for RRT were metabolic abnormalities (acidosis and hyperkalemia), anuria, and fluid overload. In all cases continuous venous-venous hemofiltration was implemented.

According to a recent definition, perioperative myocardial injury was diagnosed when the cTnI concentration at 1 hour after aortic declamping was greater than $0.92 \mathrm{ng} / \mathrm{mL}^{12}$

Postoperative low cardiac output syndrome (LOS) was defined as the need for a postoperative intra-aortic balloon pump or inotropic support for longer than 30 minutes in the intensive care unit to maintain systolic blood pressure at greater than $90 \mathrm{~mm} \mathrm{Hg}$.

Operative mortality was defined as all deaths occurring within 30 days from surgical intervention.

The European System for Cardiac Operative Risk Evaluation (EuroSCORE $)^{13}$ was derived to assess differences in patients' risk profiles.

\section{Statistical Analysis}

Continuous variables are shown as medians with interquantile ranges (IQR). All categorical data were displayed as percentages. Comparisons were made with Mann-Whitney rank-sum tests and $\chi^{2}$ tests as appropriate. Nonnormally distributed variables were log transformed when required.

Receiver operating characteristic (ROC) curve analysis was used to assess the accuracy of postoperative serum CK and myogloblin concentrations to discriminate patients with AKI or requiring RRT. Comparison of areas under the ROC curve was used identify the value with the best accuracy that was further used for the final analysis.

The Spearman rank test was used to assess unadjusted associations between AKI and other potential confounding factors, which were selected on the basis of a literature review and clinical plausibility. These variables included (1) demographic characteristics, such as age, sex, and body mass index; (2) clinical risk factors, including preoperative GFR, diabetes mellitus, hypertension, peripheral vascular disease, preoperative New York Heart Association class III/IV, left ventricular ejection fraction of less than 0.50 , myocardial infarction within 30 days, and emergency surgical intervention or cardiac angiography within 24 hours before surgical intervention; (3) preoperative medications, such as angiotensin-converting enzyme inhibitors/ angiotensin receptor blockers (ACEIs/ARBs) and statins; (4) procedural characteristics, such as the number of grafts per patient and CPB time; and (5) postoperative variables, including perioperative myocardial injury and red blood cell (RBC) transfusion rate.

A stepwise multivariate logistic regression analysis was performed, adjusting for all confounding factors significantly associated with AKI at univariate analysis, to assess the independent effect of covariates on postoperative AKI. The variance inflation factor was used to assess multicollinearity among variables. Variance inflation factor values exceeding 5.0 were regarded as indicating multicollinearity. When present, multicollinearity was addressed by (1) removing variables with the weaker relationship with the dependent variable or (2) combining variables.

Model-fit analysis was evaluated with the Hosmer-Lemeshow goodness-of-fit statistic. Odds ratios (ORs) and their associated $95 \%$ confidence intervals (CIs) were estimated. The Statistical Package for the Social Sciences, version 11 (SPSS, Inc, Chicago, Ill), was used for statistical analysis. 
TABLE 1. Clinical and procedural characteristics of patients according to the occurrence of AKI

\begin{tabular}{|c|c|c|c|}
\hline \multirow[b]{2}{*}{ Variables } & \multicolumn{2}{|c|}{ AKI } & \multirow[b]{2}{*}{$P$ value } \\
\hline & $\begin{array}{c}\text { No } \\
(n=436)\end{array}$ & $\begin{array}{c}\text { Yes } \\
(\mathbf{n}=295)\end{array}$ & \\
\hline \multicolumn{4}{|l|}{ Demographics } \\
\hline $\begin{array}{r}\text { Age median }(\mathrm{y}), \\
\text { median }(\mathrm{IQR})\end{array}$ & $66(58-72)$ & $69(62-74)$ & $<.0001$ \\
\hline Female sex $(\%)$ & 15.6 & 19.7 & .09 \\
\hline BMI $(\mathrm{kg} / \mathrm{m})$, median $(\mathrm{IQR})$ & $26(24-29)$ & $26(24-29)$ & .3 \\
\hline \multicolumn{4}{|l|}{ Clinical risk factors } \\
\hline $\begin{array}{l}\text { Preoperative GFR } \\
\left(\mathrm{mL} / \mathrm{min} / 1.73 \mathrm{~m}^{2}\right) \\
\text { median }(\mathrm{IQR})\end{array}$ & $68(57-81)$ & $62(49-76)$ & .0001 \\
\hline Diabetes mellitus (\%) & 37.4 & 41.7 & .3 \\
\hline Hypertension $(\%)$ & 91.3 & 94.9 & .059 \\
\hline $\begin{array}{l}\text { Peripheral vascular } \\
\text { disease }(\%)\end{array}$ & 14.9 & 13.9 & .7 \\
\hline $\begin{array}{l}\text { Preoperative NYHA } \\
\text { functional class } \\
\text { III-IV }(\%)\end{array}$ & 14.2 & 19.0 & .08 \\
\hline $\begin{array}{l}\text { Left ventricular ejection } \\
\text { fraction }<0.50(\%)\end{array}$ & 28.4 & 37.5 & .02 \\
\hline $\begin{array}{l}\text { Prior myocardial infarction } \\
\text { within } 30 \mathrm{~d}(\%)\end{array}$ & 36 & 44 & .03 \\
\hline Emergency operation (\%) & 10.3 & 18.3 & .0025 \\
\hline $\begin{array}{l}\text { Catheterization within } 24 \mathrm{~h} \\
\text { before operation }\end{array}$ & 11.2 & 20.6 & .007 \\
\hline $\begin{array}{l}\text { Additive EuroSCORE, } \\
\text { median (IQR) }\end{array}$ & $5.0(3.0-8.0)$ & $7.0(4.0-9.0)$ & $<.0001$ \\
\hline \multicolumn{4}{|l|}{ Preoperative medications } \\
\hline ACEI/ARB (\%) & 64.2 & 54.3 & .009 \\
\hline Statins $(\%)$ & 73.6 & 75.6 & .6 \\
\hline \multicolumn{4}{|l|}{ Procedural characteristics } \\
\hline $\begin{array}{l}\text { No. of grafts/patient, } \\
\text { median (IQR) }\end{array}$ & $3(2.0-3.0)$ & $3(3.0-3.0)$ & .11 \\
\hline $\begin{array}{l}\text { CPB time (min), median } \\
\text { (IQR) }\end{array}$ & $101(82-120)$ & $107(89-128)$ & .0073 \\
\hline \multicolumn{4}{|l|}{ Postoperative variables } \\
\hline $\begin{array}{l}\text { Perioperative myocardial } \\
\text { injury }(\%)\end{array}$ & 13.8 & 20.8 & .017 \\
\hline $\begin{array}{l}\text { Low cardiac output } \\
\text { syndrome }(\%)\end{array}$ & 5.1 & 11.3 & .003 \\
\hline $\begin{array}{l}\text { Red blood cell transfusion } \\
\quad \text { rate }(\%)\end{array}$ & 56.7 & 71.2 & .0001 \\
\hline
\end{tabular}

$A K I$, Acute kidney injury; $I Q R$, interquantile range; $B M I$, body mass index; $G F R$, glomerular filtration rate; NYHA, New York Heart Association; ACEI, angiotensinconverting enzyme inhibitor; $A R B$, angiotensin receptor blocker; $C P B$, cardiopulmonary bypass.

\section{RESULTS}

\section{Incidence of AKI}

Overall, 295 (40.3\%) of 731 patients had AKI. Patients' risk profiles were significantly worse in patients with AKI. They were older and more often had a recent myocardial infarction. In addition, they were more likely to have reduced GFR, a left ventricular ejection fraction of less than 0.50 , emergency surgical intervention, and catheterization within 24 hours before surgical intervention. ACEIs/ARBs were more likely taken by patients who did not experience AKI. Finally, AKI was associated with a prolonged CPB time, a higher incidence of preoperative myocardial injury, and a higher rate of RBC transfusion (Table 1). Thirty-one $(4.2 \%)$ of 731 patients required RRT. The median postoperative length of intensive care unit stay in survivors with AKI was 5.4 days (IQR, 3.96.8 days) compared with 2.0 days (IQR, 1.0-3.0 days) for patients without AKI $(P<.0001)$. The median postoperative length of intensive care unit stay in survivors requiring RRT was 11 days (IQR, 4-26 days) compared with 2.0 days (IQR, 1.0-3.0 days) for patients who did not require RRT $(P<.0001)$.

\section{Operative Mortality}

Overall, the operative mortality rate was $21(2.8 \%)$ of 731. The operative mortality rate for patients with AKI was $6.4 \%$ compared with $0.45 \%$ for patients without AKI $(P<.0001)$ and $37 \%$ for patients who required postoperative dialysis compared with $1.2 \%$ for patients who did not $(P<.0001)$.

\section{Unadjusted Association Between Markers of Muscle Injury and AKI}

As previously reported, we observed serum myoglobin concentrations peak early after surgical intervention (at 1 hour after declamping, $426 \mu \mathrm{g} / \mathrm{mL}$ [IQR, 308-622 $\mu \mathrm{g} / \mathrm{mL}$; at 24 hours, $344 \mu \mathrm{g} / \mathrm{mL}$ [IQR, 189-657 $\mu \mathrm{g} / \mathrm{mL}$ ]; at 48 hours, $171 \mu \mathrm{g} / \mathrm{mL}$ [IQR, $92-313 \mu \mathrm{g} / \mathrm{mL}])$. Meanwhile, the serum CK concentration had its peak concentration later (at 1 hour after declamping, $332 \mathrm{U} / \mathrm{L}$ [IQR, 227-489 U/L]; at 24 hours, $625 \mathrm{U} / \mathrm{L}$ [IQR, 417-1039 U/L]; at 48 hours, 475 U/L [IQR, 283-836 U/L]). Comparison of ROC curves (Figure 1) showed that serum myoglobin concentration had a better accuracy for discrimination of patients with AKI than CK concentration at any time (Table 2). Serum myoglobin concentration at 1 hour after declamping had the best predictive power when compared with serum myoglobin concentrations at 24 and 48 hours. Therefore this value was further used to assess the association between the extent of perioperative muscle injury and the incidence of AKI.

The preoperative serum myoglobin concentration was similar among patients with and without AKI $(156 \mu \mathrm{g} / \mathrm{mL}$ [IQR, 104-193 $\mu \mathrm{g} / \mathrm{mL}$ ] vs $149 \mu \mathrm{g} / \mathrm{mL}$ [IQR, 99-188], $P=.23)$. Postoperatively, AKI was associated early with a higher increase in serum myoglobin concentration just 1 hour after aortic declamping $(534 \mu \mathrm{g} / \mathrm{mL}$ [IQR, 354-733 $\mu \mathrm{g} / \mathrm{mL}$ ] vs $377 \mu \mathrm{g} / \mathrm{mL}$ [IQR, 278-528 $\mu \mathrm{g} / \mathrm{mL}$ ], $P<.0001$ ), which persisted at 24 hours $(481 \mu \mathrm{g} / \mathrm{mL}$ [IQR, 264-930 $\mu \mathrm{g} / \mathrm{mL}$ ] vs $275 \mu \mathrm{g} / \mathrm{mL}$ [IQR, $163-476 \mu \mathrm{g} / \mathrm{mL}$ ], $P<.0001$ ) and 48 hours $(256 \mu \mathrm{g} / \mathrm{mL}$ [IQR, $115-453 \mu \mathrm{g} / \mathrm{mL}$ ] vs 142 $\mu \mathrm{g} / \mathrm{mL}[\mathrm{IQR}, 120-170 \mu \mathrm{g} / \mathrm{mL}], P<.0001)$. Indeed, serum 


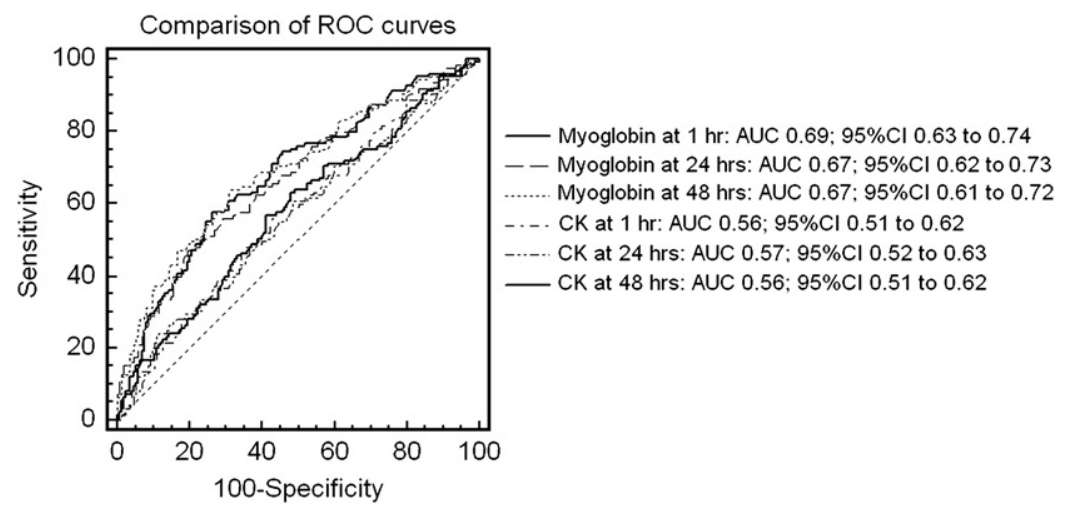

FIGURE 1. Serum myoglobin concentration in patients with acute kidney injury (dashed line) and those who did not have acute kidney injury (solid line). $R O C$, Receiver operating characteristic; $A U C$, area under the receiver operating characteristic curve; $C I$, confidence interval; $C K$, creatine kinase.

creatinine concentration shows a slight decrease at 1 hour manly related to hemodilution, and renal function deterioration was evident in the AKI group only 24 hours after declamping (Figure 2). A marked postoperative increase in serum myoglobin concentration was seen at 1 hour after declamping $(980 \mu \mathrm{g} / \mathrm{mL}$ [IQR, 568-1818 $\mu \mathrm{g} / \mathrm{mL}$ ] vs 331 $\mu \mathrm{g} / \mathrm{mL}$ [IQR, $187-628 \mu \mathrm{g} / \mathrm{mL}], P<.0001)$ and at 24 hours $(600 \mu \mathrm{g} / \mathrm{mL}$ [IQR, 305-1516 $\mu \mathrm{g} / \mathrm{mL}$ ] vs $289 \mu \mathrm{g} / \mathrm{mL}$ [IQR, $192-303 \mu \mathrm{g} / \mathrm{mL}], P<.0001)$ in patients who required RRT in comparison with that seen in patients who did not. ROC curve analysis showed that an early serum myoglobin concentration of greater than $465 \mu \mathrm{g} / \mathrm{mL}$ predicted AKI with a sensitivity of $60 \%$ and a specificity of $67 \%$, and a value greater than $790 \mu \mathrm{g} / \mathrm{mL}$ predicted RRT requirement with a sensitivity of $67 \%$ and a specificity of $74 \%$ (area under the ROC curve, $0.65 ; 95 \% \mathrm{CI}, 0.61-0.70 ; P=.04$ ).

When patients with perioperative myocardial injury were excluded ( $\mathrm{n}=117 / 731$ [16\%]), AKI continued to be associated with a higher increase in serum myoglobin concentration at 1 hour after aortic declamping $(490 \mu \mathrm{g} / \mathrm{mL}$ [IQR, $331-656 \mu \mathrm{g} / \mathrm{mL}$ ] vs $370 \mu \mathrm{g} / \mathrm{mL}$ [IQR, 270-557 $\mu \mathrm{g} / \mathrm{mL}$ ], $P=.0002)$ and at 24 hours $(463 \mu \mathrm{g} / \mathrm{mL}[\mathrm{IQR}, 259-930$ $\mu \mathrm{g} / \mathrm{mL}$ ] vs $293 \mu \mathrm{g} / \mathrm{mL}$ [IQR, $166-523 \mu \mathrm{g} / \mathrm{mL}], P<.0001)$, with no significant differences in cTnI concentrations at 1 hour after aortic declamping $(0.6 \mathrm{ng} / \mathrm{mL}$ [IQR, $0.3-0.8] \mathrm{vs}$ $0.6 \mathrm{ng} / \mathrm{mL}$ [IQR, $0.4-0.8 \mathrm{ng} / \mathrm{mL}$ ], $P=.27$ ), at 24 hours $(1.2 \mu \mathrm{g} / \mathrm{mL}$ [IQR, $0.7-2.8 \mu \mathrm{g} / \mathrm{mL}$ ] vs $1.3 \mu \mathrm{g} / \mathrm{mL}$ [IQR, $0.7-3.0 \mu \mathrm{g} / \mathrm{mL}], P=.67)$, and at 48 hours $(0.9 \mu \mathrm{g} / \mathrm{mL}$

TABLE 2. Pairwise comparison of ROC curves for myoglobin versus CK power to predict $A K I$ at 1, 24, and 48 hours after aortic declamping

\begin{tabular}{lcccc}
\hline & $\triangle$ AUC & SE & $\mathbf{9 5} \%$ CI & $P$ value \\
\hline $1 \mathrm{~h}$ & 0.114 & 0.0362 & $0.0381-0.180$ & $<.001$ \\
$24 \mathrm{~h}$ & 0.104 & 0.0276 & $0.0503-0.159$ & $<.001$ \\
$48 \mathrm{~h}$ & 0.109 & 0.0288 & $0.0578-0.171$ & .003 \\
\hline
\end{tabular}

$R O C$, Receiver operating characteristic; $C K$, creatine kinase; $A K I$, acute kidney injury; $A U C$, area under the receiver operating characteristic curve; $S E$, standard error; $C I$, confidence interval.
[IQR, 0.3-2.1 $\mu \mathrm{g} / \mathrm{mL}$ ] vs $1.0 \mu \mathrm{g} / \mathrm{mL}$ [IQR, $0.5-3.1 \mu \mathrm{g} / \mathrm{mL}$ ], $P=.5)$.

\section{Predictors of AKI}

After adjusting for confounding factors, serum myoglobin concentration at 1 hour was found to independently predict postoperative AKI (OR, $1.0011[1 \mu \mathrm{g} / \mathrm{mL}$ increase]; 95\% CI, $1.0003-1.0019 ; P=.005)$, and this result persisted when patients with perioperative myocardial infarction were excluded from the analysis (OR, $1.0007 ; 95 \% \mathrm{CI}$, $1.0002-1.0009 ; P=.01)$. When early postoperative serum myoglobin concentration was considered as a dichotomous variable, a cutoff value of greater than $465 \mu \mathrm{g} / \mathrm{mL}$ was associated with a 2.6-fold increase in AKI (95\% CI, 1.7-4.0; $P<.0001)$. Instead, postoperative cTnI concentration failed to show an independent effect on the incidence of AKI when it was entered either as perioperative myocardial injury (OR in enter method, $1.002 ; 95 \% \mathrm{CI}, 0.97-1.03 ; P=.87$ ) or as a continuous variable (OR in enter method, $1.00[1 \mathrm{ng} / \mathrm{mL}$ increase]; 95\% CI, 0.97-1.03; $P=.82$ ).

Other independent predictors of postoperative AKI (Table $3)$ were baseline GFR $(P=.02)$, emergency surgical intervention $(P=.002)$, catheterization within 24 hours before surgical intervention $(P=.008)$, preoperative ACEIs/ ARBs $(P=.04)$, CPB time $(P=.007)$, postoperative LOS $(P=.001)$, and RBC transfusion $(P=.03)$.

The multivariate model significantly predicted the occurrence of AKI (model $\chi^{2}=45, P<.0001$ ). The model was well calibrated among deciles of observed and expected risk (Hosmer-Lemeshow $\chi^{2}=13, P=.19$ ).

Early postoperative serum myoglobin concentration also predicted postoperative RRT requirement $(\mathrm{OR}, 1.0005$ per $1 \mu \mathrm{g} / \mathrm{mL}$ increase; $95 \% \mathrm{CI}, 1.0002-1.0009 ; P=.003)$ after adjusting for baseline GFR (OR, 0.96 per $1 \mathrm{~mL} / \mathrm{min} / 1.73 \mathrm{~m}^{2}$ decrease; 95\% CI, 0.93-0.99; $P=.01)$ and LOS (OR, 2.3; 95\% CI, 1.31-5.9; $P=.04$; model: $\chi^{2}=17 ; P=.0006$ ). When early postoperative serum myoglobin concentration was considered as a dichotomous variable, a cutoff value 


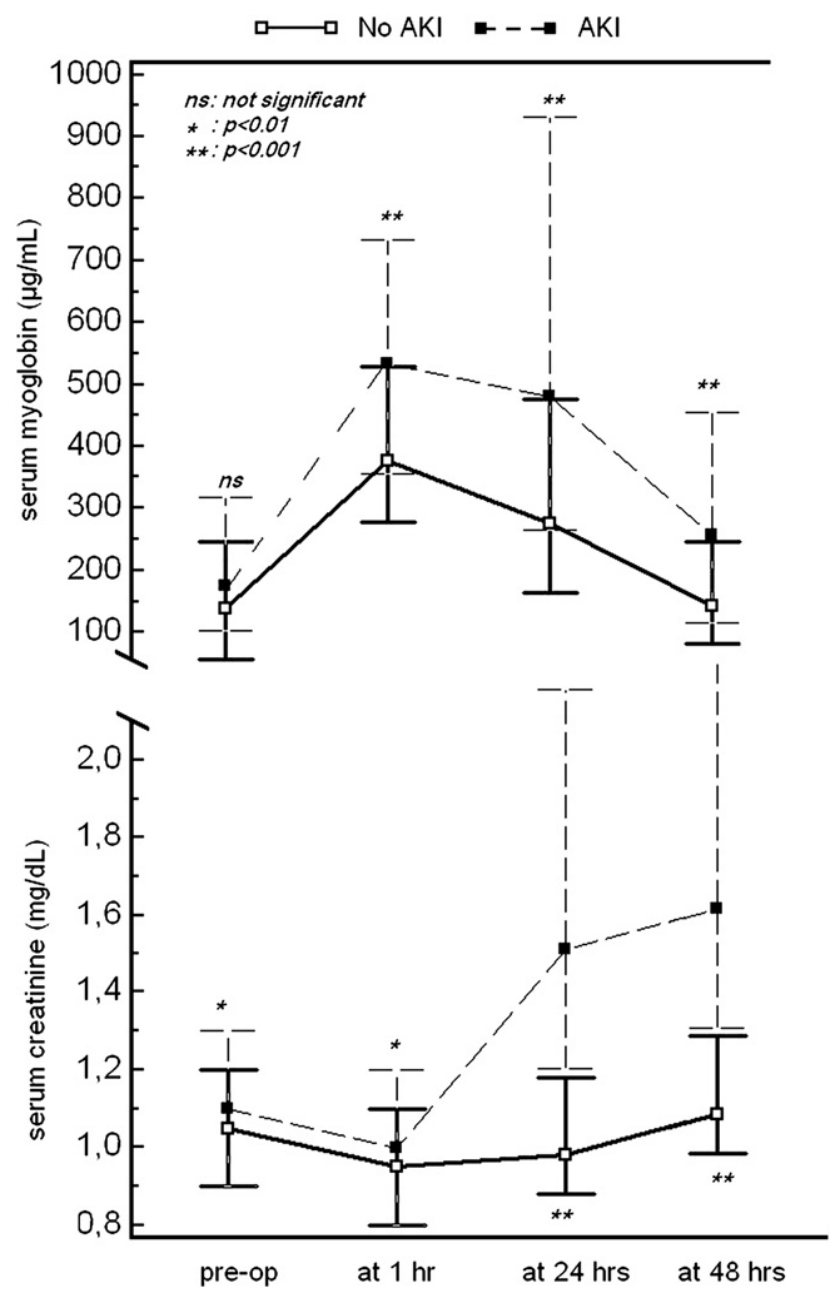

FIGURE 2. Kinetics of myoglobin and creatinine concentrations in patients with acute kidney injury (AKI; solid line) and those without AKI (dashed line) at baseline (0), 1 hour, 24 hours, and 48 hours after declamping, respectively.

of greater than $790 \mu \mathrm{g} / \mathrm{mL}$ was associated with a 4.2 -fold increase of RRT requirement (95\% CI, 1.4-12; $P=.01$ ).

Figure 3 is useful to obtain the probability to require RRT according to early serum myoglobin concentrations in patient with and without chronic kidney disease (GFR $<60$ $\mathrm{mL} / \mathrm{min} / 1.73 \mathrm{~m}^{2}$ ). As expected, higher values were better tolerated in patients without chronic kideny disease.

\section{Predictors of Postoperative Serum Myoglobin Concentration}

A stepwise linear regression analysis was implemented to identify independent predictors of postoperative serum myoglobin concentration (log transformed). They were age $(r=0.17, P=.0003), \mathrm{CPB}$ time $(r=0.211, P=.0001), \mathrm{ex}-$ tracardiac arteriopathy $(r=0.10, P=.04)$, body mass index $(r=0.14, P=.001)$, and perioperative myocardial infarction $(r=0.15, P=.004$; model multiple: $r=0.33, P<.001)$.
TABLE 3. Logistic regression* ${ }^{*} \uparrow$ analysis of factors related to the occurrence of postoperative AKI

\begin{tabular}{|c|c|c|c|}
\hline Variables & $\begin{array}{c}\text { Adjusted } \\
\text { odds ratio }\end{array}$ & $95 \% \mathrm{CI}$ & $\begin{array}{c}P \\
\text { value }\end{array}$ \\
\hline Preoperative GFR $\ddagger$ & 0.98 & $0.97-0.99$ & .002 \\
\hline Emergency operation & 2.46 & $1.36-4.45$ & .002 \\
\hline $\begin{array}{l}\text { Catheterization within } 24 \mathrm{~h} \\
\text { before operation }\end{array}$ & 1.8 & $1.1-3.8$ & .008 \\
\hline ACEI/ARB & 0.84 & $0.65-0.99$ & .04 \\
\hline CPB time $\S$ & 1.005 & $1.001-1.02$ & .007 \\
\hline Postoperative LOS & 2.5 & $1.3-4.1$ & .001 \\
\hline Postoperative RBC transfusion & 1.62 & $1.04-2.51$ & .03 \\
\hline $\begin{array}{l}\text { Serum myoglobin concentration } 1 \mathrm{~h} \\
\text { after declamping (continuous) } \|\end{array}$ & 1.001 & $1.0003-1.001$ & .005 \\
\hline
\end{tabular}

When patients with perioperative myocardial infarction were excluded from the analysis, postoperative serum myoglobin concentration continued to be associated with age $(r=0.19, P=.0001)$, CPB time $(r=0.24, P=.0001)$, extracardiac arteriopathy $(r=0.17, P=.01)$, and body mass index $(r=0.21, P<.001)$.

A further analysis including 73 patients undergoing isolated off-pump CABG during the study period was performed to better characterize the relationship among CPB, myocyte enzyme release, and the incidence of AKI.

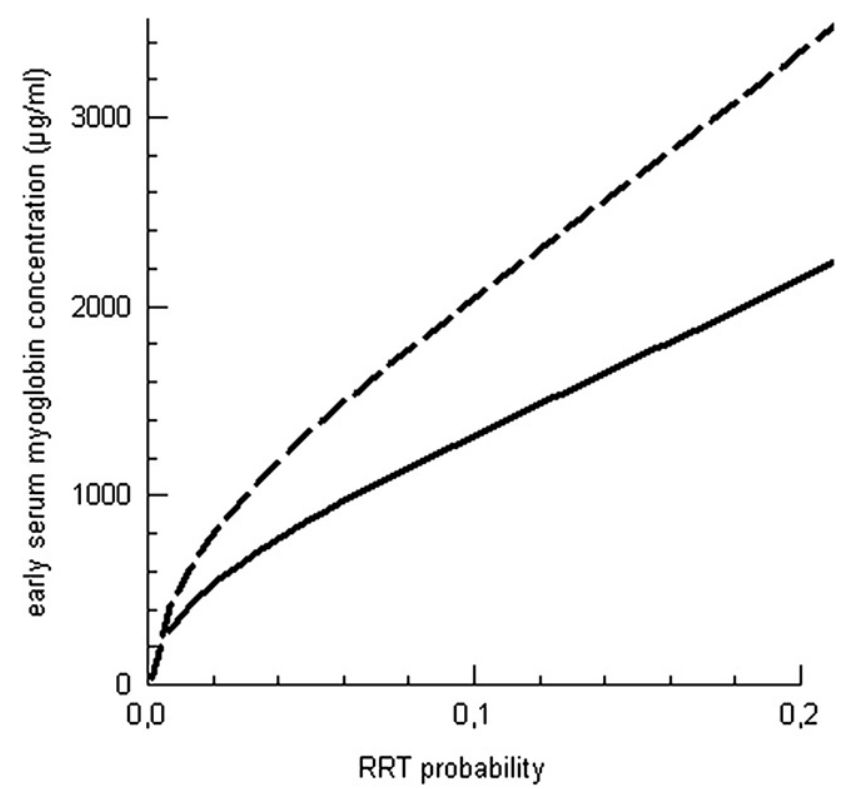

FIGURE 3. Prediction curves for renal replacement therapy $(R R T)$ requirement for patients without chronic kidney disease* (dashed line) and patients with chronic kidney disease $\nmid$ (solid line). $*$ Model definition: $\mathrm{Y}=\mathrm{a}+\mathrm{b} / \mathrm{ln}$ (x). Adjusted coefficient of multiple regression $\mathrm{R}_{\mathrm{a}}{ }^{2}=0.59$. $\dagger$ Adjusted coefficient of multiple regression $\mathrm{R}_{\mathrm{a}}{ }^{2}=0.58$. 
The off-pump group showed a significantly lower incidence of AKI $(n=20 / 73[27.4 \%])$ when compared with the on-pump group $(P=.03)$, and this advantage was confirmed after adjusting for other relevant risk factors (OR, $0.45 ; 95 \% \mathrm{CI}, 0.25-0.81 ; P=.008$ ). Interestingly, offpump procedures were associated with significantly lower serum myoglobin $(343 \mu \mathrm{g} / \mathrm{mL}$ [IQR, 192-695 $\mu \mathrm{g} / \mathrm{mL}$ ]) and CK (447 U/L [IQR, 297-762 U/L]) peak concentrations when compared with on-pump procedures $(P=.01$ and $P=.0006$, respectively).

\section{DISCUSSION}

Rhabdomyolysis is well known to be responsible for renal dysfunction in clinical situations, such as burns and severe muscle trauma. ${ }^{3}$ In fact, with muscle injury, large quantities of myoglobin leak into the circulation and precipitate in the renal glomerulus, causing renal tubular obstruction and leading to renal damage. ${ }^{3}$ Recently, it has been suggested that myoglobinemia-induced AKI might play an important role in surgical settings, such as urologic ${ }^{4,5}$ and thoracoabdominal aortic $^{6,7}$ surgery.

In patients undergoing $\mathrm{CABG}$ with $\mathrm{CPB}$, the prevailing theory is that kidney injury is mainly caused by hypoperfusion or activation of immune responses. ${ }^{1}$ The present study suggested that the increases in laboratory findings seen with muscle injury postoperatively, especially serum myoglobin concentrations, predicts the incidence of AKI and RRT requirement, as reported in other surgical setting. ${ }^{4-7}$ Our findings showed that perioperative myocardial injury cannot totally explain the occurrence of increased myoglobinemia because an increased serum myoglobin concentration persisted when patients with perioperative myocardial injury were excluded from the analysis. Because no other relevant sources of myoglobin are currently known besides skeletal muscle, ${ }^{3}$ these results suggest an important role of skeletal muscle breakdown and necrosis in determining increased myoglobinemia after CABG. The risk of rhabdomyolysis might be relevant when concurrent risk factors, such as obesity, ${ }^{14}$ peripheral vascular disease, and prolonged operative time, ${ }^{8}$ are present.

The diagnosis of rhabdomyolysis is confirmed by laboratory studies. CK concentrations are the most sensitive indicator of myocyte injury in patients with rhabdomyolysis. ${ }^{3}$ However, the present study demonstrated that in patients undergoing $\mathrm{CABG}$, postoperative myoglobin concentration had the best accuracy to predict the occurrence of AKI when compared with CK concentration. This result is not surprising because increased serum myoglobin concentrations are the main cause in the development of rhabdomyolysis-induced AKI. In fact, they can precipitate and cause renal tubular obstruction, leading to renal damage. $^{3}$

As previously reported, ${ }^{12}$ we found that serum myoglobin concentrations rapidly increased after surgical intervention.
Thus its early determination, just before 1 hour after declamping, might permit us to promptly recognize patients at higher risk for AKI. In fact, patients with a more evident increase in early postoperative serum myoglobin concentration were more likely to present with a deterioration of renal function during the following 48 hours, and this detrimental effect persisted after adjusting for relevant confounding factors, such as preoperative renal function, catheterization within 24 hours before surgical intervention, and perioperative medications.

The off-pump technique has been consistently associated with a reduction in the incidence of $\mathrm{AKI}^{2}{ }^{2}$ In addition, offpump CABG is related to a significantly lower concentration of myoglobin and CK postoperatively when compared with conventional procedures on CPB. ${ }^{12}$ Our analysis confirmed these previously reported results, thus suggesting that the benefit of avoiding CPB on renal function might be partially explained by lower myoglobin concentrations after surgical intervention.

\section{Mechanisms of Myoglobin-Induced AKI}

Myoglobin is a low-molecular-weight heme protein that is abundant in cardiac and skeletal muscles but not in smooth muscle. Myoglobin is rapidly released from the necrotic muscle, with subsequent rapid renal clearance. High serum myoglobin concentrations have been shown to play a dominant role in the pathogenesis of rhabdomyolysis-induced renal failure. ${ }^{3}$ The basic mechanisms involved in its pathophysiology include the following ${ }^{15-19}$ : (1) renal constriction and ischemia, (2) myoglobin cast formation in the distal convoluted tubules, and (3) direct cytotoxic action of myoglobin on the epithelial cells of the proximal convoluted tubules. ${ }^{15}$ The coexisting hypovolemia and acid $\mathrm{pH}$ of urine, because of metabolic acidosis, are regulating factors that intensify the nephrotoxic action of myogloblin.

\section{Possible Sources of Extracardiac Myoglobin Increase After CABG}

Although initially recognized solely as a posttraumatic sequela, nontraumatic causes of rhabdomyolysis, including surgical operations, are now hypothesized. A main mechanism advocated for intraoperative rhabdomyolysis is skeletal muscle ischemia caused by localized compression during extended periods of immobilization, particularly in patients with hypotension. It is possible that direct and prolonged compression of gluteal and back muscles against the operating table, accompanied by a patient's overweight status, might led to significant rhabdomyolysis during prolonged operative time, and this process might be particularly enhanced by CPB-related hypotension.

A further consideration is the possibility that pre-existing peripheral vascular disease might increase the risk for rhabdomyolysis after CABG, exacerbating peripheral hypoperfusion. 


\section{Limitations of the Study}

This study has some limitations. Although we identified the association between serum myoglobin concentration and the incidence of AKI and RRT requirement, causality cannot be proved. In addition, the multivariate model was modest in prediction of postoperative RRT because of the small number of events. Finally, we did not attempt to identify direct muscular insult or injury in this group of patients, particularly given the difficulty of assessing muscular symptoms beyond gross movement and sensation during the first 3 postoperative days in this population of patients, who are often still sedated during this time period. Although few other sources of myoglobin are currently known besides cardiac and skeletal muscle, the evidence for occurrence of "textbook" rhabdomyolysis beyond documented myoglobinemia is admittedly circumstantial in these patients.

\section{Clinical Implications}

The present analysis has several important therapeutic implications. This study found a strong correlation between myoglobin release and the incidence of AKI after CABG. Because myoglobin reaches its peak concentration early after surgical intervention, its determination permits us to promptly identify patients at higher risk for AKI. In these patients an appropriate treatment should be promptly started. Aggressive fluid replacement with saline is beneficial in minimizing the occurrence of renal failure requiring dialysis. ${ }^{3}$ Alkalinization through the use of bicarbonate is controversial but might reduce formation of myoglobin crystals and lipid peroxidation. ${ }^{3}$

Finally, to reduce the risk of rhabdomyolysis in high-risk patients, such as older obese subjects with peripheral vascular disease, it might be useful to maintain a higher flow and arterial pressure during $\mathrm{CPB}$ and, when feasible, to limit the duration of the operation.

Further studies are needed to better characterize risk factor interactions and to develop novel therapeutic strategies in the prevention and treatment of myoglobinemia-related AKI after CABG.

\section{References}

1. Rosner MH, Okusa MK. Acute kidney injury associated with cardiac surgery. Clin J Am Soc Nephrol. 2006;1:19-32.

2. Nigwekar SU, Kandula P, Hix JK, Thakar CV. Off-pump coronary artery bypass surgery and acute kidney injury: a meta-analysis of randomized and observational studies. Am J Kidney Dis. 2009;54:413-23.

3. Huerta-Alardín AL, Varon J, Marik PE. Bench-to-bedside review: rhabdomyolysis—an overview for clinicians. Crit Care. 2005;9:158-69.

4. Hiratsuka Y, Ishii T, Takeuchi F, Okadome A, Taira H. The risk of elevated creatinine kinase and myoglobulinemia due to incised muscles in patients who underwent urological surgery. J Urol. 2003;170:119-21.

5. Bruce RG, Kim FH, McRoberis W. Rhabdomyolysis and acute renal failure as a complication following radical perineal prostatectomy. Urology. 1996;47: 427-30.

6. Miller CC III, Villa MA, Achouh P, Estrera AL, Azizzadeh A, Coogan SM, et al. Intraoperative skeletal muscle ischemia contributes to risk of renal dysfunction following thoracoabdominal aortic repair. Eur J Cardiothorac Surg. 2008;33:691-4.

7. Miller CC III, Villa MA, Sutton J, Lau D, Keyhani K, Estrera AL, et al. Serum myoglobin and renal morbidity and mortality following thoracic and thoracoabdominal aortic repair: does rhabdomyolysis play a role? Eur $J$ Endovasc Surg. 2009;37:388-94.

8. Alterman I, Sidi A, Azamfirei L, Copotoiu A, Tiberiu E. Rhabdomyolysis: another complication after prolonged surgery. J Clin Anesth. 2007;19:64-6.

9. Levey AS, Greene T, Kusek JW, Beck GJ. A simplified equation to predict glomerular filtration rate from serum creatinine. J Am Soc Nephrol. 2000; 11:A0828.

10. National Kidney Foundation. K/DOQI clinical practice guidelines for chronic kidney disease: evaluation, classification, and stratification. Kidney disease outcome quality initiative. Am J Kidney Dis. 2002;39(suppl):S1-246.

11. Mehta RL, Kellum JA, Shah SV, Molitoris BA, Ronco C, Warnock DG, et al. Acute Kidney Injury Network (AKIN): report of an initiative to improve outcomes in acute kidney injury. Crit Care. 2007;11:R31.

12. Chowdhury UK, Malik V, Yadav R, Seth S, Ramakrishnan L, Kalaivani M, et al. Myocardial injury in coronary artery bypass grafting: on-pump versus off-pump comparison by measuring high-sensitivity C-reactive protein, cardiac troponin $\mathrm{I}$, heart-type fatty acid-binding protein, creatinine kinase-MB and myoglobin release. J Thorac Cardiovasc Surg. 2008;135:1110-9.

13. Nashef SAM, Roques F, Michel P, Gauducheau E, Lemeshow S, Salamon R. The EUROScore study group. European system for cardiac operative risk evaluation (EuroSCORE). Eur J Cardiothorac Surg. 1999;16:9-13.

14. Bostanjian D, Anthone GJ, Hamoui N, Crookes PF. Rhabdomyolysis of gluteal muscles leading to renal failure: a potentially fatal complication of surgery in the morbidly obese. Obes Surg. 2003;13:302-5.

15. Abassi ZA, Hoffman A, Better O. Acute renal failure complicating muscle crush injury. Semin Nephrol. 1998;18:558-65.

16. Chatzizisis YS, Misirli G, Hatzitolios AI, Giannoglou GD. The Syndrome of rhabdomyolysis: complications and treatment. Eur J Int Med. 2008;19:568-74.

17. Heyman SN, Rosen S, Fuchs S, Epstein FH, Brezis M. Myoglobinuric acute renal failure in rat: a role for medullary hypoperfusion, hypoxia and tubular obstruction. J Am Soc Neprhol. 1996;7:1066-74.

18. Thadhani R, Pascual M, Bonventre JV. Acute renal failure. N Engl J Med. 1996; 334:1448-60.

19. Zager RA, Gamelin LM. Pathogenetic mechanisms in experimental hemoglobinuric acute renal failure. Am J Physiol. 1989;256:F446-55. 